\title{
Geography, Maps, and the Annals: 67 Years of History
}

\author{
Robert Hickey (he/him \\ Central Washington University \\ rhickev@cwu.edu
}

Elvin Delgado (he/him)

Central Washington University

elvin.delgado@cwu.edu

Geographers are often asked "what is geography?", and the number of answers to this question nearly equals the number of geographers. We (and others) argue that it is the spatial dimension that makes geography different, and that to do geography, one must communicate spatial information. Cartography is one of the key forms of spatial communication. However, the geographic literature often lacks maps. To examine this, we reviewed 67 years of the Annals of the American Association of Geographers to test any trends in the presencelabsence of maps, the influence of editors, and how any trends related to changes in the field of geography. On average, 24\% of the papers published did not contain maps. Roughly speaking, papers from the 1950s, mid-1970s through the 1980s, and from 2000-present were the least likely to contain maps. Papers in the 1960s, early 1970s, and mid-1990s contained the most. The influence of editors on the percentage of papers published without maps was significant, but weak. We found a relationship between the changes in numbers of papers with maps and broad changes in the field of geography. There was a slight increase in the number of publications that included maps during the quantitative revolution after World War II, which declined during the discipline's shift toward social and critical geography in the 1960s and 1970s. In 2001, the format of the Annals changed from publishing all the articles in one section to dividing the publications in four thematic sections with different editors. From 2001-2017, the Physical Geography and Environmental Sciences section was the most likely to have maps (11.9\% of articles without maps) while the People, Place, and Regions section was the least likely (47.7\% without maps). Overall, the changes in the percentage of articles without maps can largely be explained by changes in the fields of geography and cartography - up to about the year 2000.

KEYWORDS: geography; cartography; mapping; Annals of the American Association of Geographers

"May a preselective bent toward geography be recognized before it asserts itself as deliberate election? The first, let me say most primitive and persistent trait, is liking maps and thinking by means of them. We are empty handed without them in lecture room, in study, in the field. Show me a geographer who does not need them constantly and want them about him, and I shall have my doubts as to whether he has made the right choice of life." (Sauer 1956, 288-289)

\section{INTRODUCTION}

CARTOGRAPHy CAN BE VIEWED as simply another language, a construct designed to communicate ideas from one person to another-in this case, spatial information (Silayo 2002). Thus, it would seem that cartography is a necessary tool for any geographer. Geography's spatial tradition (Pattison 1964) and emphasis on spatial thinking pervades the field's literature, and provides ample evidence for mapping being integral to geography (Beck 1967;
Borchert 1987; Wheeler 1998; Goodchild and Anselin 2000; Golledge 2002). Muehrcke goes further by saying: "Geographers who avoid maps needlessly limit their ability to conduct geographical research and communicate geographical information ... Indeed, if geography as a university discipline survives intact into the next century, it is more likely to be through closer association than through further disassociation with modern methods of geographic 
cartography" (1981, 404). He further contended that with the vast improvements being made in software and available data, maps had more to offer the geographer.

In our personal observation, cartography is considered by some to be simply a technical skill, and, more recently, one that anyone with some GIS skills will pick up. However, this was not always the case, as Moriarty (1965) described a cartographer as someone between a draftsman (pure technique) and a communicator (to the near exclusion of technical skills). More recently, however, the International Cartographic Association defines cartography as "the discipline dealing with the art, science and technology of making and using maps" (International Cartographic Association 2021). For a detailed historical account of the changing definitions of maps and cartography see Kraak and Fabrikant (2017) or Monmonier (2015). Certainly, the highly technical requirements of pen-and-ink cartography tended to drive people away (Muehrcke 1981). Similarly, early GIS imposed a high technical bar upon users. Today, though, GIS is relatively user friendly, and online mapping services put cartography within the grasp of almost everyone with internet/computer access and some spare time. Along these lines, Robinson, Robinson, and Muerhcke (1977) argued that cartography had changed from a technique to an identifiable scholarly and scientific field. They made predictions related to both an increase in computer techniques and an increase in demand for maps-particularly temporary, computer-based maps (examples include the use of Google Earth or the route maps we all use to get from place to place).

While we, the authors, have anecdotally noticed that a considerable number of "geography" papers in the literature lack maps, are there any trends? To answer this question, we reviewed sixty-seven years of the premier US geography journal, the Annals of the American Association of Geographers (Annals), which we selected as the most representative of the discipline, at least within the US. Our review sought to test the hypothesis that there is a dearth of maps within published geographic literature and that the presence of maps is declining. Thus, the goal of this article is to answer three inter-related research questions: (1) what is the incidence of maps in the Annals?, (2) has the presence/absence of maps changed over time?, and (3) if so, why do these trends exist?

In the context of this paper, we will use the ICA's definition of cartography: "the discipline dealing with the art, science and technology of making and using maps" (International Cartographic Association 2021). We are also specifically focused on academic cartography (Edney 2015) as it is represented in the Annals.

In the next section we discuss the historical context for our research, followed by the methods used. The fourth section presents our results in four sub-sections. First, we discuss the overall patterns in the use of maps in the Annals. Second, using Chi-square and Cramer's V statistical tests, we analyze the relationship between editorship and the number of articles published without maps. Third, we explore the number of publications by section after the Annals changed its format in 2001. Finally, we discuss the potential relationships that exist between the trends of map presence in the Annals and the historical trends in the discipline. The fifth and last section concludes with a reflection on the patterns that emerged from this analysis and suggestions for lines of future inquiry.

\section{HISTORICAL CONTEXT}

The Development OF THE HistoRy and philosophy of geographic thought is rich and complex, and a detailed description is beyond the scope of this paper (see Livingstone 1992; Martin and James 1993; Johnston 2004; Martin 2000; Holt-Jensen 2009; Cox 2014). However, for the purpose of this exercise, we will focus on three important paradigm shifts: regional geography, the quantitative revolution, and critical geography. We will connect these with McMaster and McMaster's (2002) four periods of cartographic development: incipient period, the building of a discipline, diffusion of cartographic programs, and the transition period.

Over the study period (1951-2017), geography transitioned from a regional geographical study of landscape characteristics, as it had been in the first half of the twentieth century, to a spatial analysis approach shaped by the quantitative revolution of the 1950s. Regional geography was originally focused on the idea of areal differentiation of the world (Hartshorne 1939) and later concerned with a qualitative description of the cultural landscape. The cultural landscape was the result of the interaction with and transformation of the natural characteristics of the landscape by a culture group (Sauer 1925). Maps were an important tool used by regional geographers. Nevertheless, 
the development of academic cartography during this time was known as the "incipient period" (McMaster and McMaster 2002, 306) because it was characterized by a handful of geography departments offering a couple of cartography courses and faculty focused mostly on thematic cartography.

The quantitative revolution emerged in response to criticism towards regional geography's descriptive nature and lack of scientific rigor. Peet $(2001,19)$ explains that after World War II "frustration grew with geography, as it had been, in several senses: the emphasis on regions; the lack of modern, scientific methodologies; the remoteness of the discipline from practical and social utility; thus the lack of prestige on campus and in governments and industry." Thus, quantitative geographers focused on the importance of method and theory to develop models that would help explain "spatial organization or order, spatial interaction, and spatial pattern" (Cox 2014, 28). The use of maps to depict spatial relationships was an important technique used by quantitative geographers. Wheeler $(1998,2)$ states that "the geographic mapping tradition was generally accepted if not enhanced by the so-called quantifiers of the late 1950s and the 1960s, one of the few elements the quantifiers willingly embraced from the regionalists they otherwise dismissed." During this time, the discipline of geography expanded to many universities in the United States, and this expansion allowed cartography to gain a foothold with the development of core programs (McMaster and McMaster 2002). The development of cartography continued its trajectory and was galvanized as a formal discipline within geography departments between the 1960s and 1980s, when institutions began to specialize in different areas of cartography such as cognitive or analytical cartography, numerical cartography and statistical mapping, animated cartography, and history of cartography (McMaster and McMaster 2002).

Quantitative geographers' search for objectivism, methodological rigor, and theoretical complexity opened the door for criticisms. Cox $(2014,42)$ summarizes them as follows: "the findings of the new geography often amounted to little more than statements of the obvious"; "methods were being put ahead of theory and findings of real substance"; and "the real point of research was to explain, not to generalize; a generalization in the form of a correlation or regression coefficient... was only specifying what had to be explained." Quantitative geographers were also criticized for the lack of social relevance in the research they pursued (Peet 2001). This criticism extended to cartography as well. For instance, in his discussion of the dilemma of cartographic ethics, Harley $(1990,6)$ argues that "there has to be a place in cartographic theory for interpretations that embrace a social dimension." He further contends that "the ethical failings in the way maps mediate between society and the world ... is related both to cartography's theoretical isolationism behind disciplinary barriers and to its lack of social relevance in a practical sense" (1). Along these lines, Dorling $(1998,277)$ points out that a group of cartographers in the late 1980s and 1990s stated that "many of the assertions made for mapping by quantitative geographers are a smokescreen for the actual process and origins of most maps." He further contended that "maps are about social control and are usually created to serve the design of their creators rather than to inform the public" (277).

The social issues of the late 1960s and early 1970s in the United States, such as the Vietnam War, the Civil Rights Movement, and the environmental movement, highlighted the theoretical and methodological shortcomings of quantitative geographers. A new group of social and critical geographers linked the spatially deterministic and positivist approach of quantitative geographers to their inability or unwillingness to analyze and explain social issues such as environmental pollution, social marginalization, and inequality (see Wolpert 1970; Harvey 1973; Peet 1977). Thus, a new generation of critical geographers focused their attention on these issues, moving geographic inquiry away from a spatial-quantitative focus toward a radical approach with more socially relevant research agendas such as examining imperialism (Blaut 1970) and using feminist theory to understand the invisibility of women in the field (Burnett 1973; Hayford 1974). One common theoretical approach used to address social issues at the time was Marxism, which allowed social and critical geographers to develop a theory of society that was ingrained in an economic system based on a capitalist mode of production and accumulation-a system ridden with intrinsic crises and contradiction (Harvey 1982). Not only did this line of inquiry place humans at the center of analysis, but it also allowed geographers to understand and explain issues related to uneven spatial relations (Harvey 1973), socio-environmental issues tied to political-economic processes through the lens of political ecology (Watts 1983), uneven development and the production of nature (Smith 1984), and the production of space (Lefebvre 1991), among others. The development of critical geographical 
thought mirrored a decline in the use of maps after the 1970s. Muehrcke attributed this decline to "methodological changes and ideological shifts" in the discipline (1981, 2). Wheeler $(1998,2)$ labeled Marxist geographers as being "mapphobic" because they "had little need for maps to communicate their narrative perspectives." He extends this view to all social theorists and some feminists, stating that they "seem to find maps peripheral and irrelevant, and postmodern geographers often find maps, with their categories and symbols, downright inimical to their core agendas" (2).

In the late 1960s and the 1970s, geographic information systems (GIS) and computer cartography made their advent. They were powerful new tools, but the cartographic output was exceedingly crude (especially compared to the many beautiful pen-and-ink maps that were the standard at the time). It was not until the mid-1980s and the invention of both the laser and inkjet printer that quality hardcopy map output became readily available. This time marked the beginning of what McMaster and McMaster (2002) refers to as the transition period, where cartography reached its peak and "became increasingly integrated within GIS curricula” (306).

Nonetheless, cartography as an institutional practice has been in decline over the past few decades (Millington 1999; Kain and Delano-Smith 2003; Dodge and Perkins, 2008), despite an exponential increase in map use and creation, brought on not only via GIS but also the rise of the internet, allowing for even easier distribution and use of cartographic products (e.g., Google Earth). This decline is evidenced by a significant reduction in maps in articles published by professional geographers in scientific journals (Wheeler 1998; Martin 2000; Dodge and Perkins 2008). Dodge and Perkins $(2008,1271)$ describe three wider issues confronting academic cartography in the UK: "first, the ambivalent relations between mapping and the work of geographers in the UK of the last decade; second, a continuing disregard for professional cartographic practice; and third, British geography's disassociation from newly significant approaches to the visual representation of space, and spatial practices, that are blossoming in wider social contexts and particularly on the web." When considering quality rather than quantity, a study by Kessler and Slocum (2011) examined changes in the design quality of thematic maps found in the Annals and The Geographical Journal. The authors made fine distinctions between map types and collected data back to 1900 (in the case of The
Geographical Journal), though for only one year out of every 20. Overall, they found a gradual, but statistically significant improvement in map design over time-though they were disappointed in the overall quality of maps within these journals.

The increasing use of GIS in the 1990s and 2000s was also criticized by social geographers. In his elucidation of geography, computing, and the humanities, for example, Gilbert $(1995,4)$ argues that applications of GIS have demonstrated "insensitivity to the social construction of data (particularly an over willingness to take official sources of information at face value), lack of concern for meaning and interpretation (particularly for the problematic relationship between GIS-image and reality), and little concern for the political context of geographical information (particularly the relationship between the information generated and its uses)." Others encouraged GIS researchers to consider the ethical responsibilities of their work (e.g., Crampton 1999). It is important to note that the slight downswing in cartography students and classes at this time was accompanied by a surge in GIS student numbers (Fryman 1996; Tyner 2001). However, GIS is primarily concerned with analysis, not representation (Silayo 2002) — though more recently, the cartographic capabilities of GIS have become both more user friendly and capable.

Technology has also changed the nature of cartography (Allan 1996; Fryman 1996; Keller 1996; Perkins 2008). Perhaps the most obvious way is in the proliferation of maps: they now appear everywhere: nightly news, websites, newspapers, billboards, in nearly every news venue, social media posts, on our phones, and in our cars (Robinson et al. 2017; Robinson 2019; Harrower 2004). Griffin, Robinson, and Roth $(2017,1)$ contend that "the nexus of social and technological change now makes maps and geographic data visible and useful for the most serious as well as the most mundane problems." As a result, we have seen an increase in the production of online maps by individuals who have not been trained in cartographic design. In their work on maps as landmarks of cartographic innovation, Kraak and Fabrikant $(2017,18)$ argue that "not only researchers in the geographic sciences with an increased incentive for visualizing and sharing their complex datasets, but also the general public have seized the opportunity for do-it-yourself map making." Indeed, software has made map production easier for a wider variety of people, and as a result, lower quality maps have become 
more common (Silayo 2002; Plewe 2007) and "their communicative quality is not always convincing" (Kraak and Fabrikant 2017, 18). In addition, the many print and online sites that exist today make it extremely easy to access geospatial data and distribute maps to an ever-increasing audience. Even GIS is becoming more ubiquitous, as user-friendly and capable open source programs (e.g., QGIS) become available. Consequently, there is a need for cartographers to better influence software development (Buckley and Hardy 2007; Plewe 2007; Poorthuis et al. 2020; Roth et al. 2017). In the end, "as maps and mapmaking come increasingly into mainstream society, quality design is needed more now than ever. Design is more than aesthetics; quality yields accuracy, clarity, and persuasion" (Plewe 2007, 136).

\section{METHODS}

As stated, the Annals was selected as the journal of choice for a number of reasons. First is its premier status as a general geography journal within the US. The study period (1951-2017) covered the discipline from its change from classic regional/landscape geography through the quantitative revolution and into different types of critical geography. Further, this history covers the spectrum of computer use-from computers being unavailable for mapping, to a time when computer analysis and mapping was readily available on desktop computers, tablets, and smartphones.

As the structure of the Annals evolved during the study period, the selection of material is critical. Only refereed papers were evaluated, not presidential addresses, review papers, map supplements, abstracts, or forum papers. This was done to ensure a degree of uniformity in comparison, as the definition of a peer-reviewed paper remained consistent, while other materials such as presidential addresses, varied widely. The overall pattern analysis includes the annual special editions (2009-2017); however, they are not included in the section analysis. The quality of maps was not assessed; see Kessler and Slocum (2011) for more information regarding assessing map quality.

Defining the different categories of maps was largely an exercise in elimination. This process started ambitiously with the following categories of maps initially collected for each paper: no maps, basic location maps (Figure 1), cartoon maps (schematics showing spatial relationships,

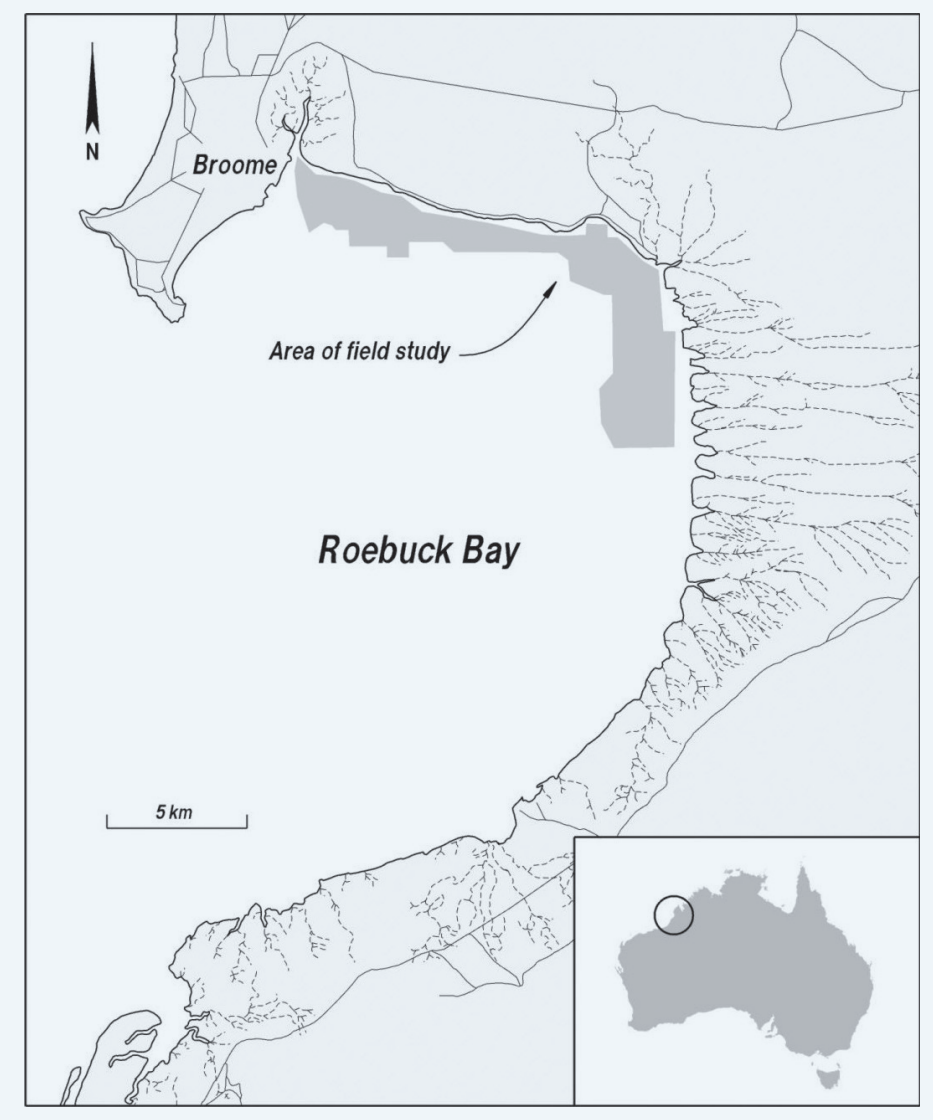

Figure 1. Sample basic location map (Carew and Hickey 2000).

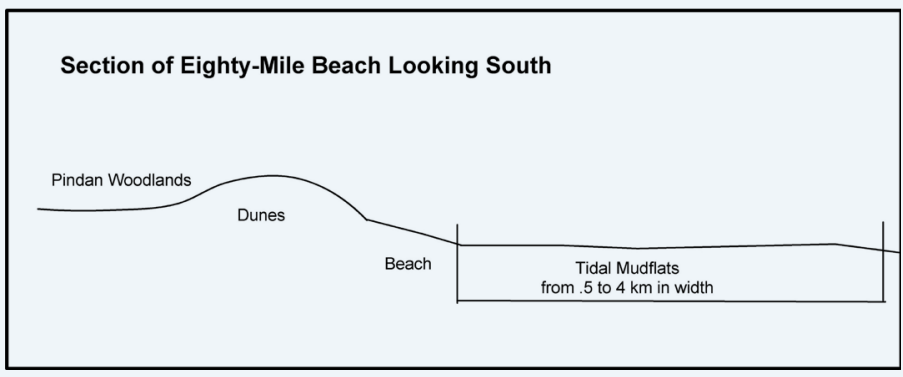

Figure 2. Sample cartoon map (Wade and Hickey 2008).

but not necessarily tied to a particular location in the real world; Figure 2), analysis results maps (Figure 3), airphotos/imagery as location maps (Figure 4), and airphoto/ imagery analysis results (Figure 5). In the end, not only were some of these relatively rare (e.g., cartoon), but distinguishing among the different types was sometimes difficult. For simplicity's sake and consistency of data collection, these groups were collapsed into three categories: no maps, location maps, and analysis maps. The guiding principle applied to differentiate between the second two categories was: are maps integral to the analysis and presentation of results, or are they present only to communicate 


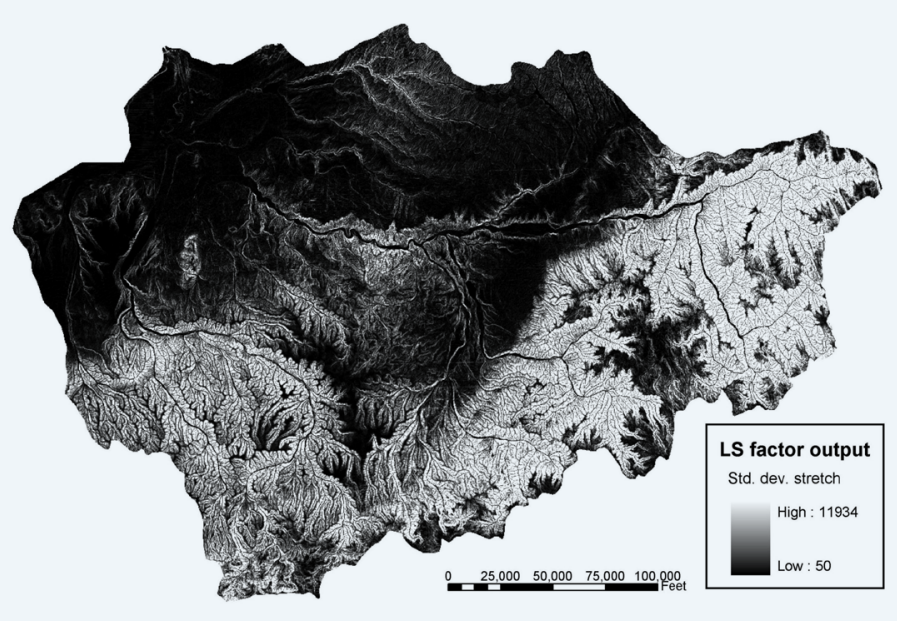

Figure 3. Sample analysis results map (Hickey et al. 2005).

basic location information? If the paper had both location and analysis maps, it was assigned to the analysis maps category.

Having defined the scope of data collection, we then reviewed 67 years of peer-reviewed articles (an interesting exercise in itself), counted the number of papers, and assigned each to a map category. The data was aggregated by year, by editor (1950-2000), and by section (2001-2017).

\section{RESULTS}

This SECTION BEgINs with a discussion of the overall patterns shown by the data between 1951 and 2017. We then quantify the relationship between the editors and the number of articles published without maps under their tenure, before reviewing the percentage of publications by sections in the Annals between 2001 and 2017. Finally, we analyze the potential relationships between the presence of maps in articles published by professional geographers, changes in cartographic methods, and the historical development of geography as a field of study.

\section{OVERALL PATTERNS}

There are definite trends in the number of refereed articles per year, and the percentage without maps. In the 1950s, 15-20 papers were published per year; this grew to 40 in the late 1960s and early 1970s (Figure 6). The number then steadily declined to 20 in 2000 . In recent years, the number of papers has skyrocketed to over 70 and as many as 93 annually, primarily driven by the introduction of an annual "special issue" in 2009. Overall, 24\% of the

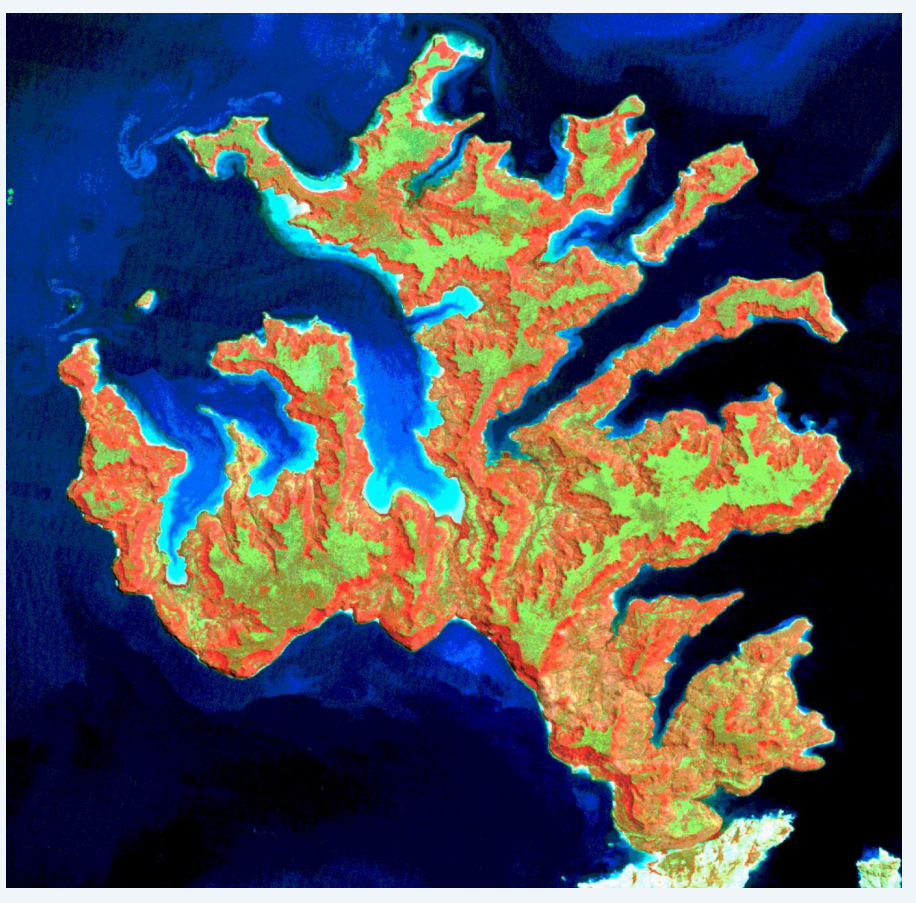

Figure 4. Sample airphoto/imagery as location map (Hickey 2005).

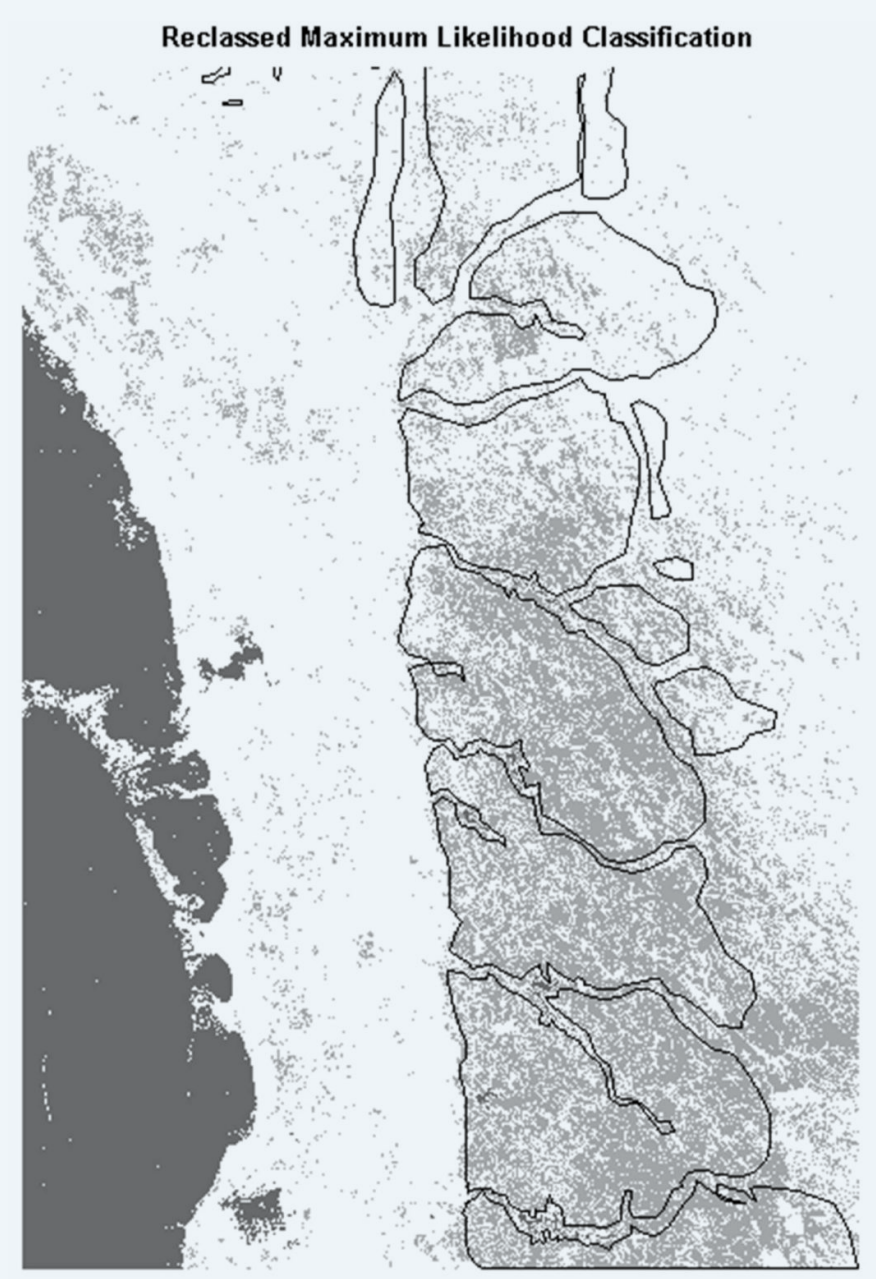

Figure 5. Sample imagery as analysis map (Hickey 2005). 


\section{Number of refereed articles per year}

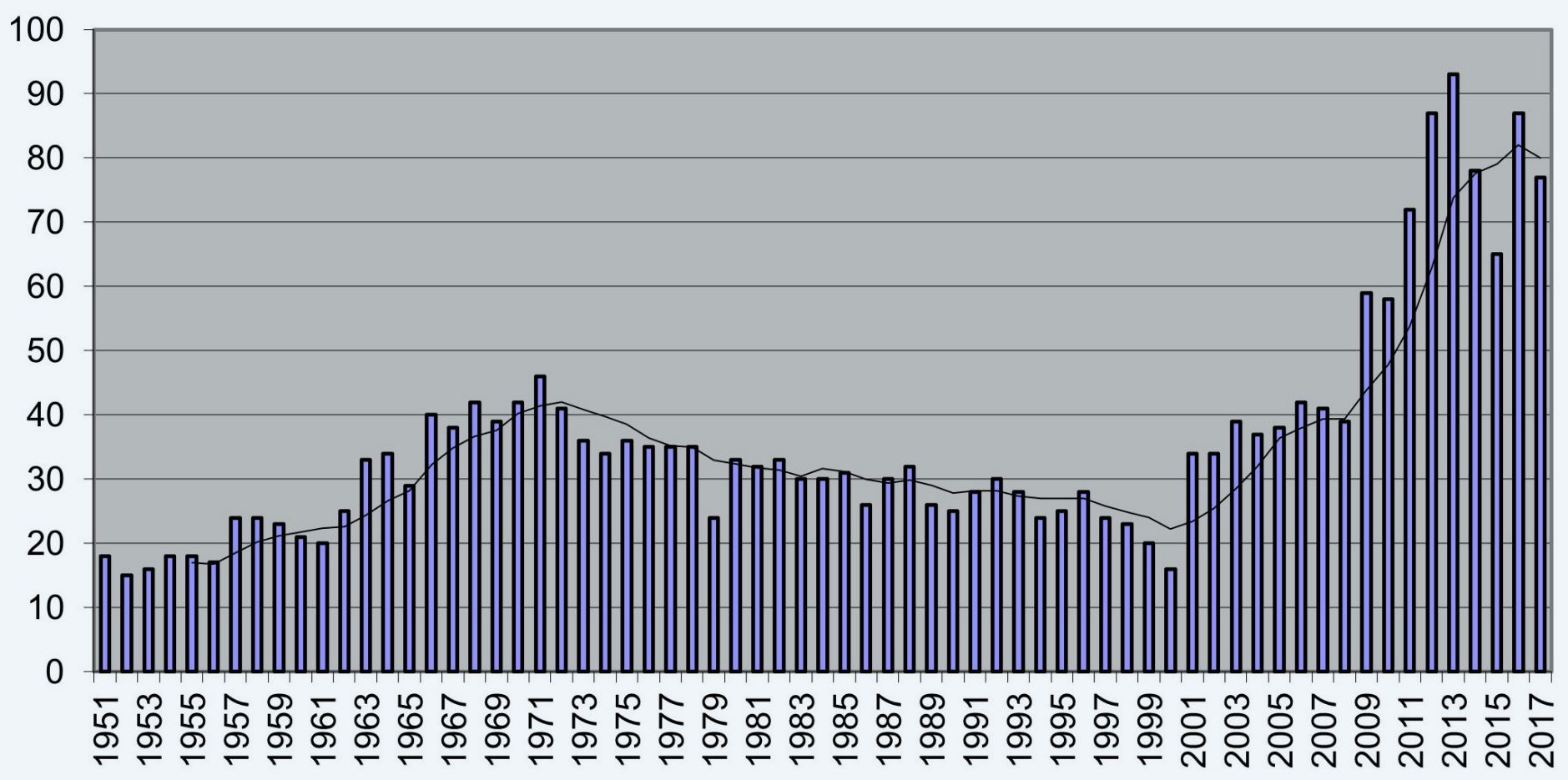

Figure 6. Chart illustrating the number of refereed papers published per year. Five-year moving average trend line included.

\section{Percent of papers without maps}

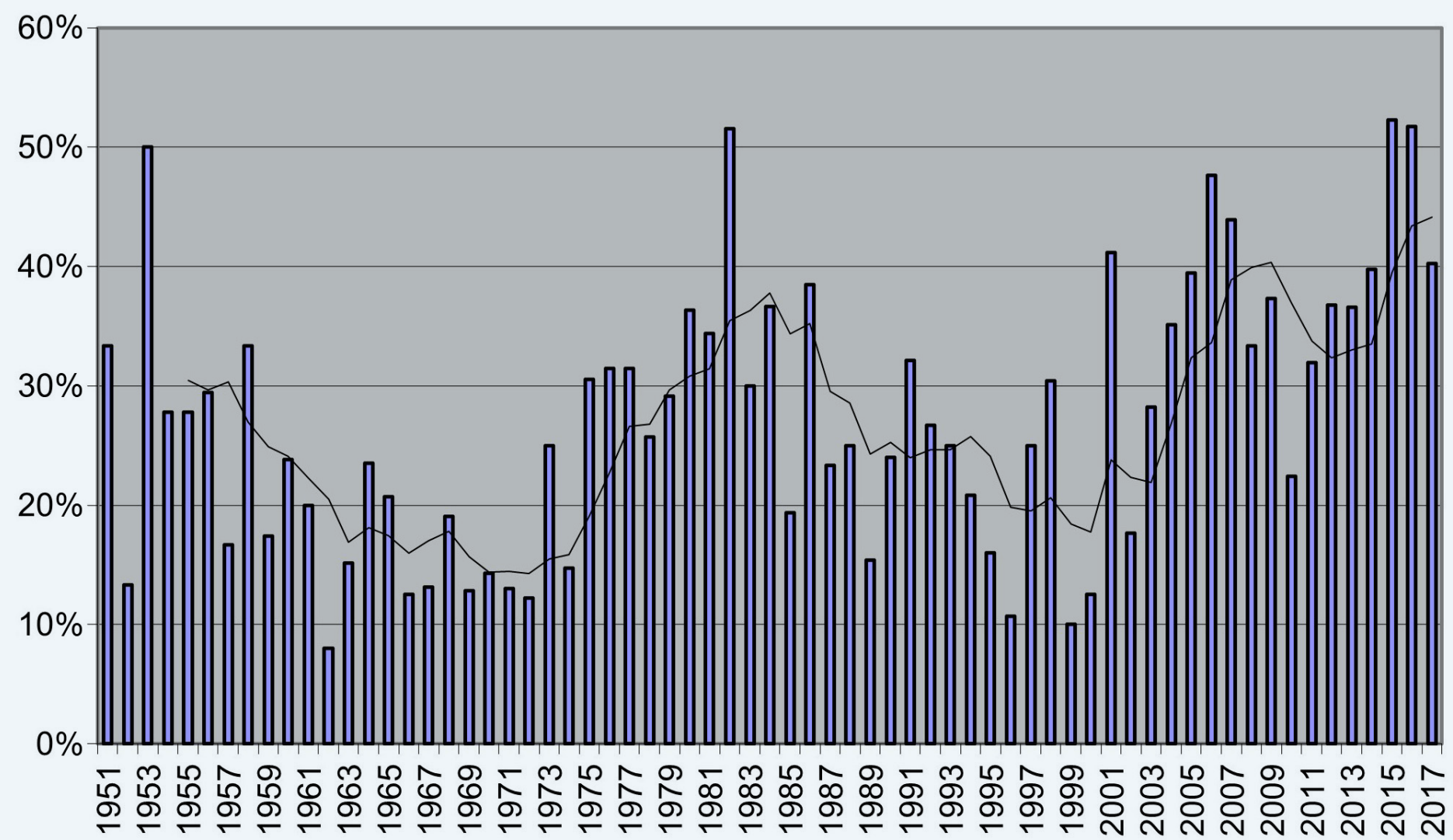

Figure 7. Chart illustrating the percentage of papers published without maps. Five-year moving average trend line included. 


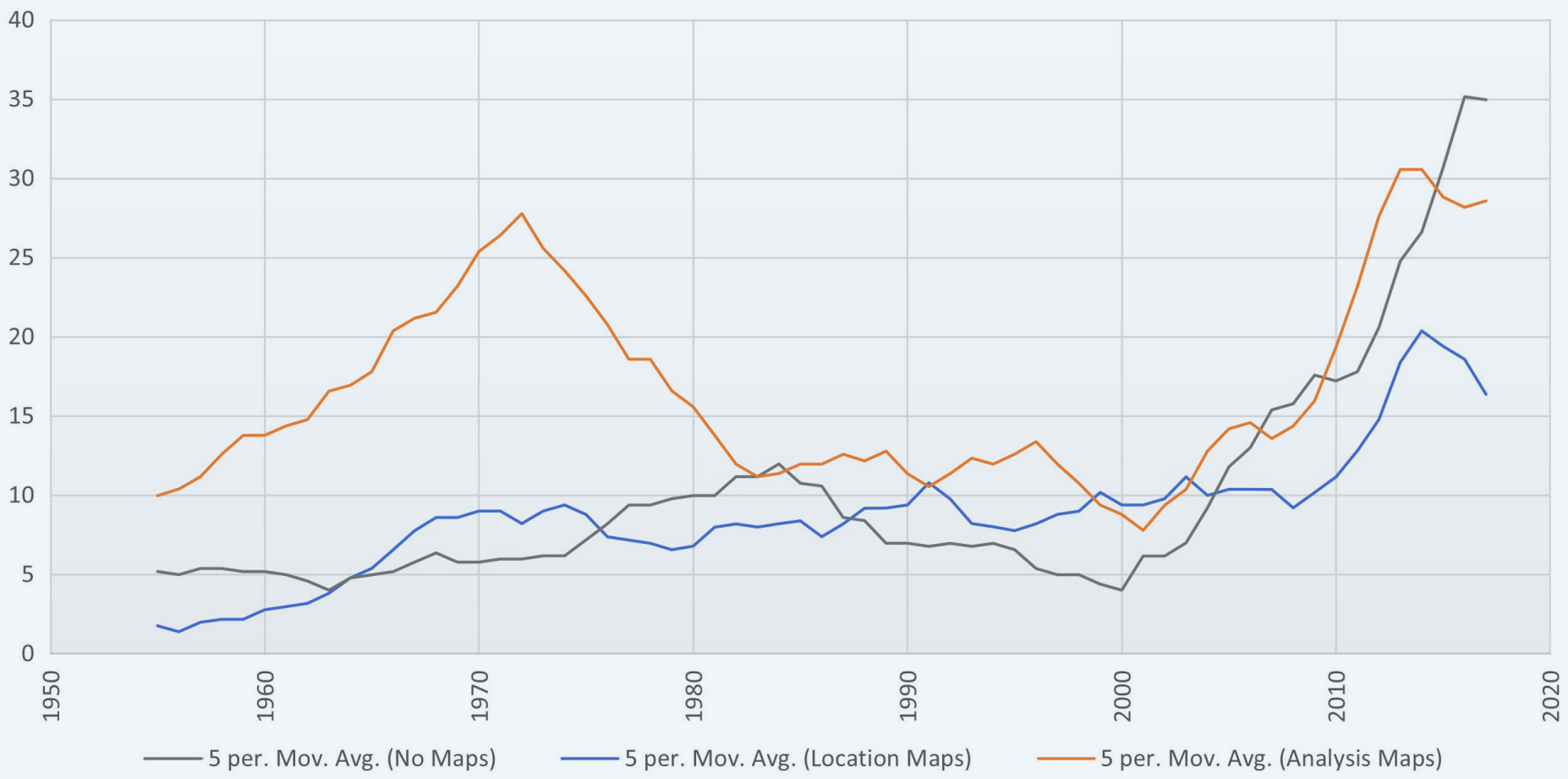

Figure 8. Chart illustrating the number of papers published per year by map category.

papers published did not contain any maps (Figure 7 ). There was a steady decrease in the perentage of articles without maps from 1950 to the mid-1960s, reaching a low point the 1960 s to mid1970s, when the percentage of articles without maps was only $\sim 15 \%$. The mid-1970s through the mid-1980s saw an increase in articles without maps, ranging from $30-40 \%$ of the published papers. From the mid-1980s to about 2000, the percentage of papers without maps in the Annals steadily declined to about $20 \%$. Since then, the presence of maps in the Annals has declined, with the percentage of articles without maps sometimes exceeding $40 \%$.

Breaking these down by map type (analysis vs. location maps) shows some interesting patterns (Figures 8 and 9). There was a steadily increasing percentage of

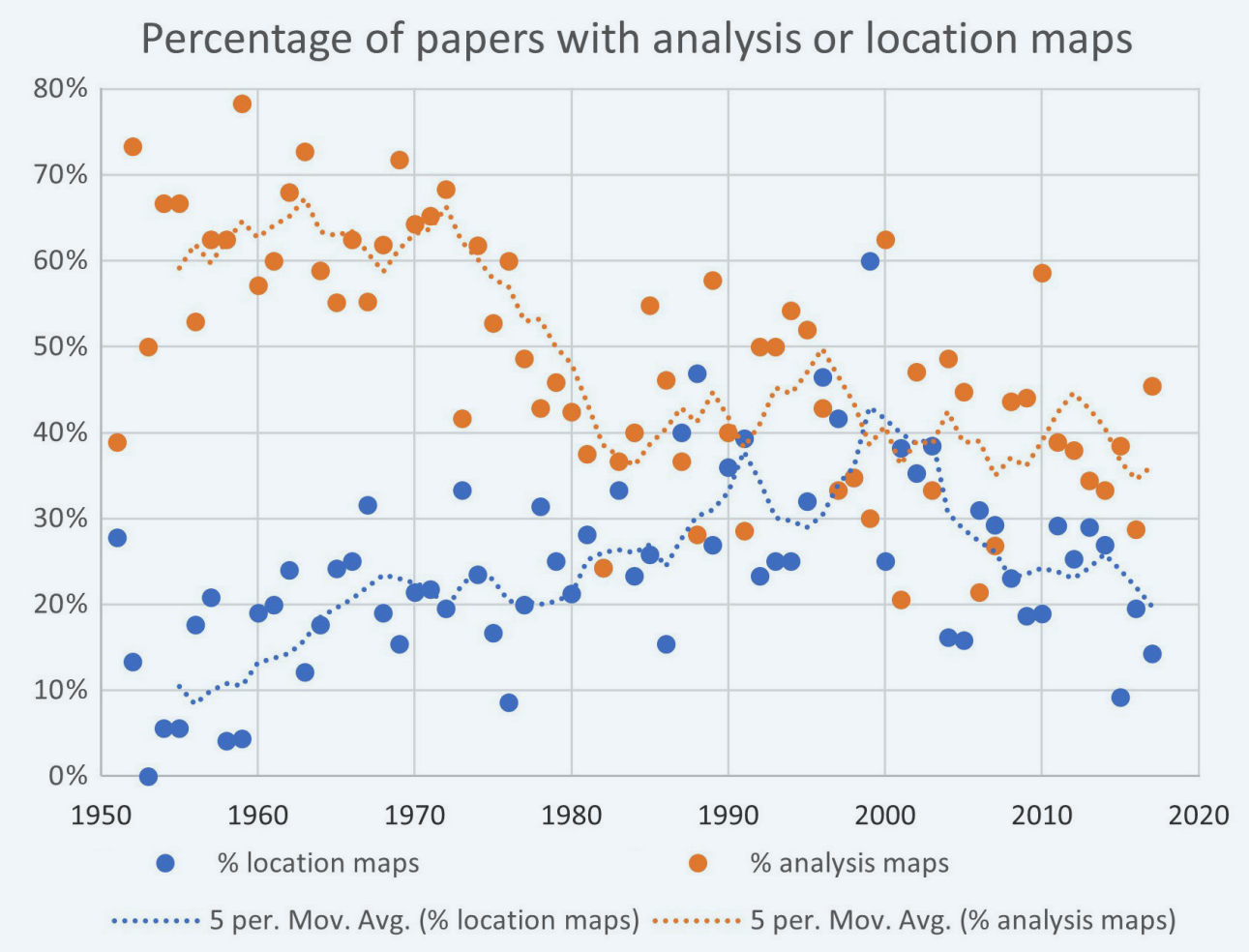

Figure 9. Chart illustrating the percentage of papers with analysis or location maps. Five-year moving average trend lines included. 


\begin{tabular}{|c|c|c|c|c|c|c|}
\hline Editor(s) & Dates & Years & $\begin{array}{l}\text { Papers } \\
\text { without maps }\end{array}$ & $\begin{array}{l}\text { Papers with } \\
\text { location maps }\end{array}$ & $\begin{array}{l}\text { Papers with } \\
\text { analysis maps }\end{array}$ & Total Papers \\
\hline Kendall & $1951-1954$ & 4 & 21 & 8 & 38 & 67 \\
\hline Kollmorgen & $1955-1960$ & 6 & 31 & 15 & 81 & 127 \\
\hline Platt & 1961-1963 & 3 & 11 & 14 & 53 & 78 \\
\hline Spencer & 1964-1969 & 6 & 37 & 49 & 136 & 222 \\
\hline Hart & 1970-1975 & 6 & 42 & 53 & 140 & 235 \\
\hline Hudson & 1976-1981 & 6 & 61 & 43 & 90 & 194 \\
\hline Conkling \& Hanson & 1982-1984 & 3 & 37 & 25 & 31 & 93 \\
\hline Hanson & 1985-1987 & 3 & 23 & 24 & 40 & 87 \\
\hline Brunn & 1988-1993 & 6 & 42 & 56 & 71 & 169 \\
\hline Earle & 1994-1996 & 3 & 12 & 27 & 38 & 77 \\
\hline Jones & 1997-1999 & 3 & 15 & 30 & 22 & 67 \\
\hline Kasperson \& Kasperson & 2000 & 1 & 2 & 4 & 10 & 16 \\
\hline totals & & 50 & 334 & 348 & 750 & 1432 \\
\hline
\end{tabular}

Table 1. Table showing the different Annals editors and the categories of papers published during their editorships.

papers with only location maps, from $\sim 10 \%$ in the 1950 s to $\sim 40 \%$ in the early 2000 s. Since then, this percentage has decreased to about $20 \%$. Over the same time, there has been a drop in the number of papers which contained analysis maps. However, it was not a steady decline. About $63 \%$ of the papers had analysis maps in the 1950s and 1960s. This number then dropped to $40 \%$ by 1980 , where it has remained.

\section{IMPACT OF EDITORS}

The Annals had 12 different editors (or pairs of editors) during the years 1951 through 2000 (Table 1); their terms ranged from 1 to 6 years. The format of the journal changed in 2001, with each section now having separate editors, thereby reducing the overall impacts of individual editors. As a result, this analysis was not done post-2001. The distribution of papers by type is shown in Table 1, while Figure 10 illustrates the percentage of papers without maps by editor. As can be seen, this percentage varies

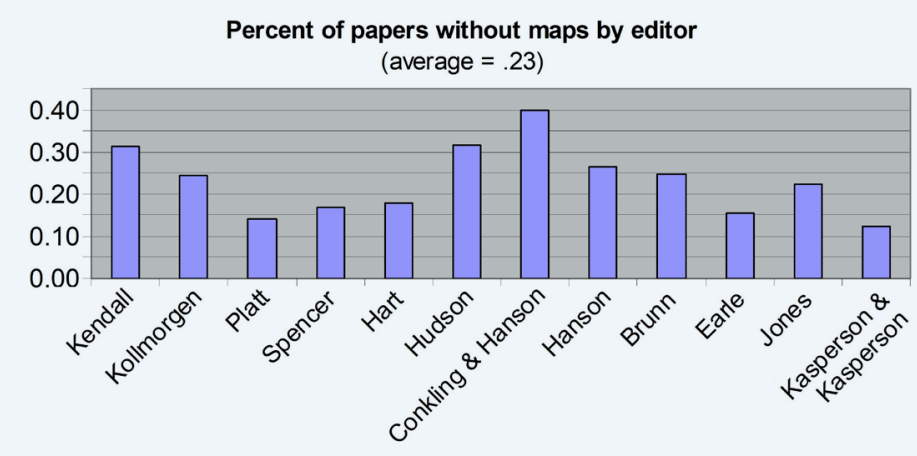

Figure 10. Chart illustrating the percentage of papers without maps by editor.

from $12.5 \%$ (Kasperson \& Kasperson) to 39.8\% (Conkling \& Hanson).

To test the relationship between editorship and the number of papers published without maps, Chi-square and Cramer's V statistical tests were used. Both tests work with categorical data; the Cramer's V is used to determine the strength of association of any significance measured 
by the Chi-square test. Because there is often a lag between papers being accepted and published, this analysis was run twice. The first time assumed no lag-that the editors were fully responsible for the papers published under their watch. In the first case (Table 2), the Chi-square value was 41.2; the Cramer's V was 0.17. The combination of these two values indicates that there is a significant, but weak, relationship between the editorship and the number of papers published without maps. The second analysis assumed a one-year lag between papers being accepted and then published (Table 3). For this analysis, the Chi-square value was 33.4; the Cramer's V was 0.16. Again, the combination of these two values indicates that there is a significant, but weak, relationship between the editorship and the number of papers published without maps.

The difference between using one year of lag or not is largely explained by 1982 , a year in which an anomalously large number of papers without maps were published (17 of 33). This difference is because the editorship switched in 1982, moving that year of few maps from Hudson's data to Conkling \& Hanson's.

It is important to note that while there is a statistically significant relationship between editorship and the number of papers published without maps, whether or not that relationship is causal is unknown. Simply put, the only way to test the influence of editors would be to have data regarding all submitted papers and some systematic background information on the editors themselves. As neither dataset is available, it is impossible to fully test the relationship between editorship and publications.

\begin{tabular}{|c|c|c|c|c|}
\hline Editor & Years & $\begin{array}{l}\text { Papers } \\
\text { without maps }\end{array}$ & $\begin{array}{l}\text { Papers with } \\
\text { maps }\end{array}$ & $\begin{array}{l}\text { Total } \\
\text { papers }\end{array}$ \\
\hline Kendall & $1951-1954$ & $21(15.6)$ & $46(51.4)$ & 67 \\
\hline Kollmorgen & $1955-1960$ & $31(29.6)$ & $96(97.4)$ & 127 \\
\hline Platt & $1961-1963$ & $11(18.2)$ & $67(59.8)$ & 78 \\
\hline Spencer & 1964-1969 & $37(51.8)$ & $185(170.2)$ & 222 \\
\hline Hart & 1970-1975 & $42(54.8)$ & $193(180.2)$ & 235 \\
\hline Hudson & 1976-1981 & $61(45.2)$ & $133(148.8)$ & 194 \\
\hline Conkling \& Hanson & 1982-1984 & 37 (21.7) & $56(71.3)$ & 93 \\
\hline Hanson & 1985-1987 & $23(20.3)$ & $64(66.7)$ & 87 \\
\hline Brunn & 1988-1993 & $42(39.4)$ & $127(129.6)$ & 169 \\
\hline Earle & 1994-1996 & 12 (18.0) & $65(59.0)$ & 77 \\
\hline Jones & 1997-1999 & $15(15.6)$ & $52(51.4)$ & 67 \\
\hline Kasperson \& Kasperson & 2000 & $2(3.7)$ & $14(12.3)$ & 16 \\
\hline total & & 334 & 1098 & 1432 \\
\hline
\end{tabular}

Table 2. Table illustrating the relationship between editors and the papers published during their tenure. Numbers in parentheses are the expected value (calculated as part of the Chi-square analysis).

\begin{tabular}{|c|c|c|c|c|}
\hline Editor & Years* & $\begin{array}{l}\text { Papers } \\
\text { without maps }\end{array}$ & $\begin{array}{l}\text { Papers with } \\
\text { maps }\end{array}$ & $\begin{array}{l}\text { Total } \\
\text { papers }\end{array}$ \\
\hline Kendall & 1952-1955 & $20(15.7)$ & $47(51.3)$ & 67 \\
\hline Kollmorgen & $1956-1961$ & $30(30.1)$ & $99(98.9)$ & 129 \\
\hline Platt & 1962-1964 & $15(21.3)$ & 76 (69.7) & 91 \\
\hline Spencer & 1965-1970 & 35 (53.7) & 195 (176.3) & 230 \\
\hline Hart & 1971-1976 & 47 (53.3) & 181 (174.7) & 228 \\
\hline Hudson & 1977-1982 & $67(44.9)$ & 125 (147.1) & 192 \\
\hline Conkling \& Hanson & 1983-1985 & $26(21.3)$ & 65 (69.7) & 91 \\
\hline Hanson & 1986-1988 & $25(20.6)$ & $63(67.4)$ & 88 \\
\hline Brunn & 1989-1994 & 35 (31.5) & $100(103.5)$ & 135 \\
\hline Earle & 1995-1997 & $13(18.0)$ & $64(59.0)$ & 77 \\
\hline Jones & $1998-2001$ & $11(13.8)$ & $48(45.2)$ & 59 \\
\hline totals & & 324 & 1063 & 1387 \\
\hline
\end{tabular}

Table 3. Table illustrating the relationship between editors and the papers published during their tenure-assuming a one year lag between acceptance and publication. Numbers in parentheses are the expected value (calculated as part of the Chi-square analysis). 


\section{Percentage of papers by section}

$60.0 \%$

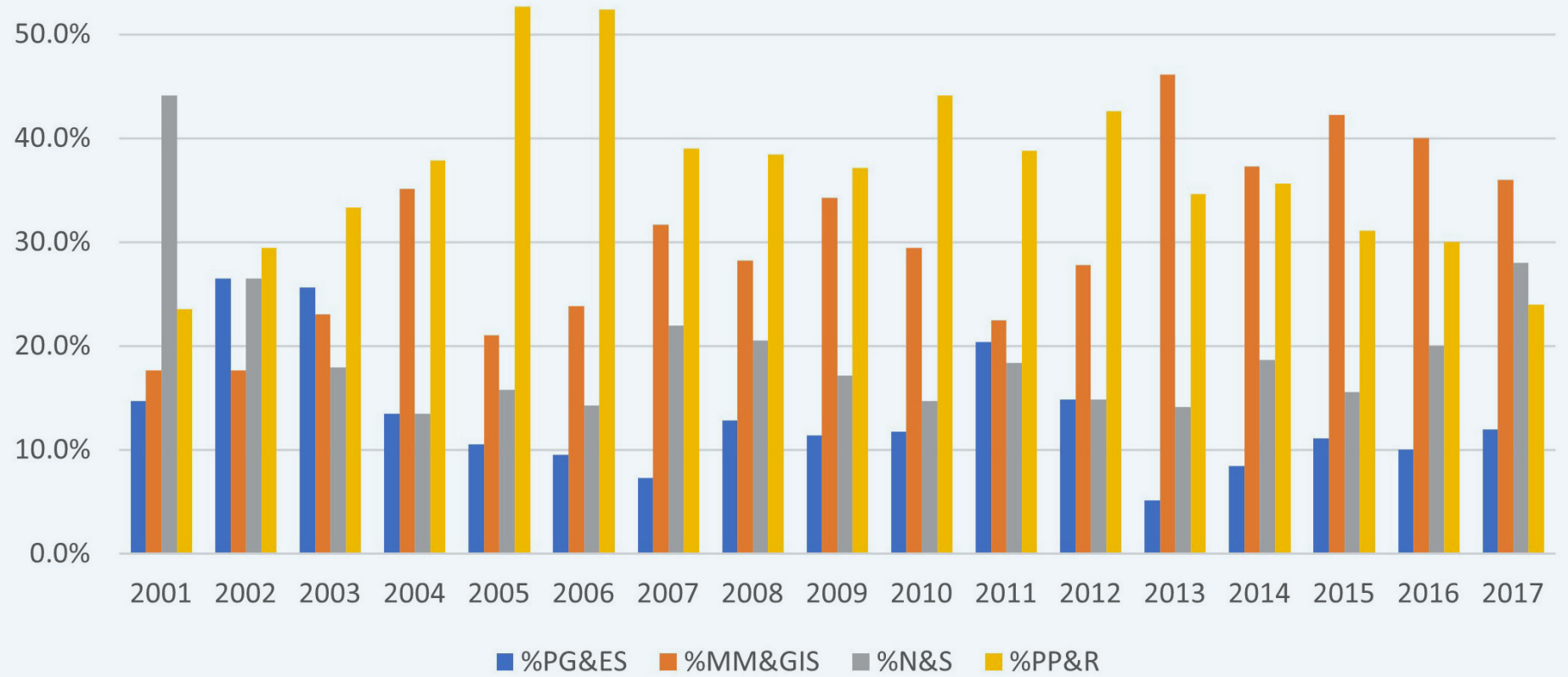

Figure 11. Chart illustrating the percentage of papers by section (2001-2017). Sections are: Physical Geography and Environmental Sciences (PG\&ES); Methods, Models, and GIS (MM\&GIS); Nature and Society (N\&S); and People, Place, and Regions (PP\&R). Special editions are excluded from this figure.

\section{MAPPING BY SECTION}

From 1951 until 2000, the Annals published all the articles under one section titled either "Articles" or "Original Articles." However, the journal changed its format in 2001 and adopted four main sections, titled: (1) Physical Geography and Environmental Sciences (PG\&ES); (2) Methods, Models, and GIS (MM\&GIS); (3) Nature and Society (N\&S); and (4)

People, Place, and Regions (PP\&R). For the purpose of this research, we analyzed the presence or absence of maps in articles published in each one of these sections from 2001 through 2017.

The total number of articles published by section during this time period was: 97 in PG\&ES, 148 in N\&S, 253 in MM\&GIS, and 280 in PP\&R. Figure 11 shows the percentage of papers published per year by section.
When examining the trends by section, some interesting patterns appear (Figure 12). Overall, PG\&ES consistently had the lowest percentage of papers without maps-for ten of the 19 years, that percentage was zero. PP\&R had the highest percentage of papers without maps at around 48\%. Both MM\&GIS (surprisingly) and N\&S fell somewhere in between. Interestingly, 2010 was anomalous: PG\&ES, N\&S, and MM\&GIS had maps in all of their papers, though overall, $22 \%$ of all papers published did not 
contain maps. The special editions (2009-2018) had relatively low percentages of papers with maps, comparable to PP\&R, though more variable. Chi-square and Cramer's V tests (53.7 and 19, respectively) were run on the numbers of papers with and without maps by section. This indicates that there is a significant relationship between the section and the presence or absence of maps.

\section{RELATIONSHIP TO THE DISCIPLINE}

"For the heart of my argument is simply that geography changes as society changes, and that the best way to understand the tradition to which geographers belong is to get a handle on the different social and intellectual environments within which geography has been practiced" (Livingstone 1992, 347).

As stated earlier, the trends discussed in this paper need to be understood in the context of the development of cartography and the history and philosophy of geographic thought in the twentieth century. We understand that the data discussed in this paper relates specifically to the Annals and is not necessarily representative of the use of maps in scientific articles published in other peer-reviewed professional journals in the discipline. The transition from regional geography to the quantitative revolution after World War II yielded a moderate increase of total articles published from 15-20 per year in the early 1950s to about 40 per year in the late 1960s and 1970s. One interesting trend observed in the data during this time period is that the slight increase in total yearly publications coincides with a decrease in the percentage of papers that did not include maps between 1951 until 1972. For instance, $50 \%$ of the 16 articles published in 1953 did not include maps. This percentage decreased to $8 \%$ of the 25 articles published in 1962. It is not surprising to see an increase in the number of publications that included maps during the quantitative revolution, when quantitative geographers were using maps to show spatial patterns and diffusion trends.

Another expected trend that we observed is the second spike in the percentage of publications that did not include maps in the 1970s and 1980s, coinciding with the advent of critical geography and its criticism of the positivist and deterministic approach in the use of maps by quantitative geographers in the 1950s. While approximately $12 \%$ of the 41 articles published in 1972 had no maps, that increased to $52 \%$ of the 33 articles published in 1982 . The percentage of articles published without maps began a somewhat consistent decline in the 1990s reaching its lowest percentage in 1999 with $10 \%$ of the 20 articles published this year. This can be explained by increasing numbers of geographers trained in GIS and computer cartography, along with improvements in software and hardware.

However, an unexpected trend in the data can be seen from the year 2000 until the end of the study period in 2017. During this time, the number of articles published per year increased from 16 in 2000 to 93 in 2013. Surprisingly, the percentage of articles published without maps increased, too, from $13 \%$ in 2000 to $52 \%$ of the 65 articles published in 2015. We would have expected an increase in the percentage of publications with maps during the development and galvanization of GIS as one of the main tools used by geographers in the United States. However, the opposite is true for the Annals.

Fluctuation in the number of maps in the Annals could be due to the availability of staff cartographers at universities, specialists who assisted with map creation. These individuals are uncommon now, as any program offering GIS classes has faculty and students who are more than capable of making maps, especially basic location maps. We offer the possibility that the increase in the number of papers without maps in the 1970s and 1980s could be because of a decrease in the number of staff cartographers available to academic geographers. Further, the decrease in numbers of articles without maps in the late 1980s and 1990s could be because of increasing numbers of GIS/computer mapping experts among faculty/students. However, since 2000 , the rapid increase in the number of articles without maps, despite easier software, more data, and more trained individuals, cannot be explained by changes within the field of cartography.

If Openshaw $(1991,626)$ was correct when he stated that "geography needs GIS as a form of elemental super-glue in order to put the pieces of geography back together again to form a coherent scientific discipline" why, then, is there an increase in publications without maps in the period when GIS was supposed to become one of the most important tools used by geographers? This question begs for the formulation of further research to identify the specific objectives and theoretical frameworks used in the papers published in the Annals during this time period. Is it possible 
that more critical and social geographers increased their publications in comparison to their counterparts during this period in the Annals? Or, perhaps, have the more spatially oriented authors chosen to publish in more specialized journals (e.g., Transactions in GIS, Photogrammetric Engineering and Remote Sensing, Cartographic Perspectives).

\section{CONCLUSIONS}

In THIS ARTICLE, we analyzed 67 years of the Annals to identify the historical trend of publications by professional geographers that did not include maps. In doing so, we hypothesized that there is a lack of maps in geography journals, and that the number of maps has been declining. To test this hypothesis, we analyzed the incidence of maps, identified whether there was a change in the number of published articles with maps, and then offered an explanation for the change that we found. The data shows interesting results.

Given geography's well-established spatial tradition, the record of mapping in the profession's premier journal was not as notable as might be expected. A large number of published papers do not contain even simple location maps: on average, $24 \%$ of the papers published between 1951 and 2017 did not contain maps at all. Annually, this percentage ranged from $8 \%$ to $52 \%$, with the 1960 s and early 1970s, and the late 1990s, being the two periods in which articles were most likely to contain maps. Since the shift in the format of the Annals in 2001, there has been a steady increase in the number of papers which do not include maps. Of the sections, articles in PG\&ES were most likely to contain a map; those in PP\&R, the least.

Overall, the patterns of map presence/absence roughly follow different historical trends in theoretical and methodological shifts in geography. For example, the data shows that the highest percentage of publications without maps coincides with the humanistic and cultural approach of the 1970s as well as the cultural turn and the emergence of critical geography in the 1980s. The emergence of better and simpler technology (i.e., GIS, graphic design software packages, printers, and computers) in the 1990s is shown in the increasing number of papers with maps. However, post-2000, the continued improvements in technology do not explain the consistent increase in the number of papers without maps.

Finally, this article opens the door for new potential lines of inquiry. For example, future work should consider comparing the results presented here with data analyzed from premier geography journals in Europe and Latin America to determine whether different trends exist. Another line of inquiry could focus on whether or not this decline of maps in the Annals represents a fundamental shift in geography away from our spatial tradition? Or is it because of the plethora of more specialized journals in which geographers publish? Finally, a comprehensive survey of academic geographers could be conducted which directly asks questions about map use and geography's spatial tradition-and how those answers translate to different specialties and publication venues within geography.

\section{REFERENCES}

Allan, Stuart. 1999. "The Digital New World Order: A View from the Private Sector." Cartography and Geographic Information Science 26 (3): 201-214. https:// doi.org/10.1559/152304099782330653.

Beck, Robert. 1967. "Spatial Meaning and the Properties of the Environment." In Environmental Perception and Behavior, edited by David Lowenthal, 18-29. Research Paper no. 109. Chicago: University of Chicago.
Blaut, James. 1970. "Geographic Models of Imperialism.” Antipode 2: 65-85. https://doi. org/10.1111/j.1467-8330.1970.tb00477.

Borchert, John. 1987. "Maps, Geography, and Geographers." The Professional Geographer 39 (4): 387389. https://doi.org/10.1111/j.0033-0124.1987.00387. 
Buckley, Aileen, and Paul Hardy. 2007. "Cartographic Software Capabilities and Data Requirements: Current Status and a Look toward the Future." Cartography and Geographic Information Science 34 (2): 155-157. https:// doi.org/10.1559/152304007781002136.

Burnett, Pat. 1973. "Social Change, the Status of Women and Models of City Form and Development." Antipode 5: 57-62. https://doi.org/10.1111/j.1467-8330.1973. tb00575.

Carew, Ross, and Robert Hickey. 2000. "Derivation of a Tidal Inundation Model to Support Environmental Research in Roebuck Bay (Western Australia).” Transactions in GIS 4 (2): 99-111. https://doi. org/10.1111/1467-9671.00041.

Cox, Kevin. 2014. Making Human Geography. New York: The Guilford Press.

Crampton, Jeremy. 1999. "Virtual Geographies: The Ethics of the Internet." In Geography and Ethics: Journeys in a Moral Terrain, edited by James D. Proctor and David M. Smith, 72-91. London: Routledge.

Dodge, Martin, and Chris Perkins. 2008. "Reclaiming the Map: British Geography and Ambivalent Cartographic Practice." Environment and Planning $A$ 40 (6): 1271-1276. https://doi.org/10.1068/a4172.

Dorling, Danny. 1998. "Human Cartography: When it is Good to Map." Environment and Planning A 30 (2): 277-288. https://doi.org/10.1068/a300277.

Edney, Matthew. 2015. "Modes of Cartographic Practice." In Cartography in the Twentieth Century, edited by Mark Monmonier, 978-980. Chicago: University of Chicago Press.

Fryman, James. 1996. "Cartographic Education in the United States and Canada." Cartographica 33 (3): 5-13. https://doi.org/10.3138/L261-211K-524P-674P.

Gilbert, David. 1995. "Between Two Cultures: Geography, Computing, and the Humanities.” Cultural Geographies 2 (1): 1-13. https://doi. org/10.1177/147447409500200101.
Golledge, Reginald. 2002. "The Nature of

Geographic Knowledge." Annals of the Association of American Geographers 92 (1): 1-14. https://doi. org/10.1111/1467-8306.00276.

Goodchild, Michael, and Luc Anselin. 2000. "Spatially Integrated Social Science: Building the Research Infrastructure." Meeting of the Association of American Geographers, Pittsburgh, PA.

Griffin, Amy L., Anthony C. Robinson, and Robert E. Roth. 2017. "Envisioning the Future of Cartographic Research." International Journal of Cartography 3 (Sup1): 1-8. https://doi.org/10.1080/23729333.2017.1 316466.

Harley, J. B. 1990. "Cartography, Ethics, and Social Theory." Cartographica 27 (2): 1-23. https://doi. org/10.3138/C211-1512-0603-XJ14.

Harrower, Mark. 2004. "A Look at the History and Future of Animated Maps.” Cartographica 3 (3): 33-42. https://doi.org/10.3138/7mn7-5132-1mw6-4v62.

Hartshorne, Richard. 1939. The Nature of Geography. Lancaster, PA: Association of American Geographers.

Harvey, David. 1973. Social Justice and the City. Baltimore, MD: Johns Hopkins University Press. 1982. The Limits to Capital. Oxford, UK: Blackwell.

Hayford, Alison. 1974. "The Geography of Women: an Historical Introduction.” Antipode 6: 1-19. https://doi. org/10.1111/j.1467-8330.1974.tb00590.x.

Hickey, Robert. 2005. "An Investigation of the Multispectral Response Patterns of West Australian Bauxite Deposits." Journal of Spatial Science 50 (2): 97-113. https://doi.org/10.1080/14498596.2005.963 5053.

Hickey, Robert, Eric Burns, John Bolte, and Diana Walker. 2005. "Development of a Statewide Erosion Vulnerability Screening Tool for Oregon.” Geography Online 5 (1). http://www.siue.edu/GEOGRAPHY/ ONLINE/.

Holt-Jensen, Arild. 2009. Geography: History and Concepts, Fourth Edition. London: Sage Publications Ltd. 
International Cartographic Association. 2021. "ICA Mission.” Accessed January 25, 2021. https://icaci.org/ mission.

Johnston, Ronald. 2004. Geography E Geographers: AngloAmerican Human Geography since 1945, Sixth Edition. London: Arnold.

Kain, Roger, and Catherine Delano-Smith. 2003. "Geography Displayed." In A Century of British Geography, edited by Ron Johnston and Michael Williams, 371-427. Oxford: Oxford University Press.

Keller, Peter. 1996. “Towards an Introductory Cartographic Curriculum for the $21^{\text {st }}$ Century." Cartographica 33 (3): 45-53. https://doi.org/10.3138/ MW82-L635-1033-60R5.

Kessler, Fritz, and Terry Slocum. 2011. "Analysis of Thematic Maps Published in Two Geographical Journals in the Twentieth Century." Annals of the Association of American Geographers 101 (2): 292-317. https://doi.org/10.1080/00045608.2010.544947.

Kraak, Menno-Jan, and Sara Fabrikant. 2017. "Of Maps, Cartography and the Geography of the International Cartographic Association." International Journal of Cartography 3 (Sup1). https://doi.org/10.1080/2372933 3.2017.1288535.

Lefebvre, Henri. 1991. The Production of Space. Translated by Donald Nicholson-Smith. Oxford: Basil Blackwell.

Livingstone, David. 1992. The Geographical Tradition, Oxford: Blackwell.

Martin, Geoffrey, and Preston James. 1993. All Possible Worlds: a History of Geographical Ideas. New York: Oxford University Press.

Martin, Ron. 2000. “In Memory of Maps.” Transactions of the Institute of British Geographers 25 (1): 3-5. http:// www.jstor.org/stable/623313.

McMaster, Robert, and Susanna McMaster. 2002. "A History of Twentieth-Century American Academic Cartography." Cartography and Geographic Information Science 29 (3): 305-321. https://doi. org/10.1559/152304002782008486.
Millington, Andrew. 1999. "Cartography, Geography and Academia." The Geographical Journal 165 (3): 253-254. https://www.jstor.org/stable/3060441.

Monmonier, Mark, ed. 2015. Cartography in the Twentieth Century. Vol. 6 of The History of Cartography. Chicago: University of Chicago Press.

Moriarty, Barry. 1965. "Current Status of Cartographic Education in American Colleges and Universities." The Professional Geographer 17 (3): 7-11. https://doi. org/10.1111/j.0033-0124.1965.007_e.x.

Muehrcke, Phillip. 1981. "Whatever Happened to Geographic Cartography?” The Professional Geographer 33 (4): 397-405. https://doi. org/10.1111/j.0033-0124.1981.00397.x.

Openshaw, Stan. 1991. "A View on the GIS Crisis in Geography, or, Using GIS to Put Humpty-Dumpty Back Together Again." Environment and Planning A 23 (5): 621-628. https://doi.org/10.1068\%2Fa230621.

Pattison, William. 1964, "The Four Traditions of Geography." The Journal of Geography 83: 10-13. https://doi.org/10.1080/00221346408985265.

Perkins, Chris. 2008. "Cultures of Map Use.” The Cartographic Journal 45 (3): 150-158. https://doi. org/10.1179/174327708X305076.

Peet, Richard. 1977. “The Development of Radical Geography in the United States." Progress in Human Geography 1 (2): 240-263. https://doi. org/10.1177/030913257700100203.

- 2001. Modern Geographical Thought. Oxford: Blackwell.

Plewe, Brandon. 2007. "Web Cartography in the United States." Cartography and Geographic Information Science 34 (2): 133-136. https://doi. org/10.1559/152304007781002235.

Poorthuis, Ate, Lucas van der Zee, Grace Guo, Jo Hsi Keong, and Bianchi Dy. 2020. "Florence: A Webbased Grammar of Graphics for Making Maps and Learning Cartography." Cartographic Perspectives 96: 32-50. https://doi.org/10.14714/cp96.1645. 
Robinson, Anthony, Urska Demšar, Antoni Moore, Aileen Buckley, Bin Jiang, Kenneth Field, Menno-Jan Kraak, Silvana Camboim, and Claudia Sluter. 2017. "Geospatial Big Data and Cartography: Research Challenges and Opportunities for Making Maps that Matter." International Journal of Cartography 3 (Sup1): 32-60. https://doi.org/10.1080/23729333.2016.1278 151.

Robinson, Anthony. 2019. "Elements of Viral Cartography." Cartography and Geographic Information Science 46 (4): 293-310. https://doi.org/10.1080/15230 406.2018.1484304.

Robinson, Arthur, Joel Morrison, and Phillip Muehrcke. 1977. “Cartography 1950-2000." Transactions of the Institute of British Geographers 2 (1): 3-18. https://www. jstor.org/stable/622190.

Roth, Robert E., Arzu Çöltekin, Luciene Delazari, Homero Fonseca Filho, Amy L. Griffin, Andreas Hall, Jari Korpi, Ismini Lokka, André Mendonça, Kristien Ooms, and Corné P. J. M. van Elzakker. 2017. “User Studies in Cartography: Opportunities for Empirical Research on Interactive Maps and Visualizations." International Journal of Cartography 3 (Sup1): 61-89. https://doi.org/10.1080/23729333.2017.1288534.

Sauer, Carl. 1925. "The Morphology of the Landscape." University of California Publications in Geography 2: 19-53.
1956. "The Education of a Geographer." Annals of the Association of American Geographers 46 (3): 287-299. https://doi.org/10.1111/j.1467-8306.1956.tb01510.x.

Silayo, Eugene. 2002. "Cartography in a GIS Environment." International Archives of Photogrammetry and Remote Sensing 34 (6/W6): 106-112.

Smith, Neil. 1984. Uneven Development: Nature, Capital, and the Production of Space. Oxford: Basil Blackwell.

Tyner, Judith. 2001. "Whither Cartography?" Cartographic Perspectives 38: 3-6. https://doi. org/10.14714/CP38.791.

Wade, Suzanne, and Robert Hickey. 2008. "Mapping Migratory Wading Bird Feeding Habitats using Satellite Imagery and Field Data, Eighty-Mile Beach, Western Australia." Journal of Coastal Research 24 (3): 759-770. https://doi.org/10.2112/05-0453.1.

Watts, Michael. 1983. Silent Violence: Food, Famine and Peasantry in Northern Nigeria. Berkeley, CA: University of California Press.

Wheeler, James. 1998. "Mapphobia in Geography? 1980-1996.” Urban Geography 19 (1): 1-5. https://doi. org/10.2747/0272-3638.19.1.1.

Wolpert, Julian. 1970. "Departures from the Usual Environment in Location Analysis." The Annals of the Association of American Geographers 50 (2): 220-229. https://doi.org/10.1111/j.1467-8306.1970.tb00717.x. 